\title{
Melting and Crystallization of a Pseudo-Binary Mixture of Polyethylene and 1,2,4,5-Tetrachlorobenzene under High Pressure
}

\author{
Chitoshi NAKAFUKU \\ Faculty of Education, Kochi University, Kochi 780, Japan
}

(Received October 26, 1984)

\begin{abstract}
High pressure differential thermal analysis (DTA) was performed for a pseudobinary mixture of polyethylene (PE) and 1,2,4,5-tetrachlorobenzene crystallized at a cooling rate of about $5 \mathrm{~K} \mathrm{~min}^{-1}$ to study the change in melting temperature $T_{\mathrm{m}}$ with pressure and composition ratio. The phase diagram of the eutectic binary mixture at elevated pressures up to $400 \mathrm{MPa}$ was determined. In the hypereutectic region of the phase diagram of PE, two endothermic peaks appeared in the DTA curve of melting and approached each other with pressure. In the hypoeutectic region, the distance between the two melting peaks increased with pressure. The pressure dependence of the eutectic point at $1 \mathrm{~atm}$ was $0.33^{\circ} \mathrm{CMPa}^{-1}$ on the average for all compositions. The DTA curve of the binary mixture under high pressure above $350 \mathrm{MPa}$ indicated that the high pressure phase usually appearing in pure PE does not appear in PE in the binary mixture. The DTA curve at $1 \mathrm{~atm}$ of a sample crystallized under high pressure suggests that the extended chain crystal (ECC), easily formed by melt crystallization of pure PE above $350 \mathrm{MPa}$, was formed only slightly in the mixture even at a PE content $90 \%$.

KEY WORDS Polyethylene / 1,2,4,5-Tetrachlorobenzene / Eutectic Mixture / Phase Diagram / High Pressure / DTA / Melting / Crystallization /
\end{abstract}

In recent years, many papers on the compatibility or solubility of polymer-polymer mixtures have been published, but only a few have dealt with eutectic binary mixtures containing crystalline polymers. Smith and Pennings $^{1-3}$ reported that polyethylene (PE) and 1,2,4,5-tetrachlorobenzene (1,2,4,5-TCB) pseudo binary mixture solidifies in eutectic form by melt-crystallization at an appropriate cooling rate at atmospheric pressure. They pointed out that the eutectic temperature and composition of the binary mixture depends significantly on the kinetic factors governing the crystallization of polymers. For samples quenched to $81{ }^{\circ} \mathrm{C}$ from the melt, the eutectic temperature is $115^{\circ} \mathrm{C}$ and the eutectic composition for the polymer volume fraction is $0.79 .^{3}$

The melting and crystallization behavior of pure PE under high pressure have been studied by many investigators. The average pressure dependence of the melting temperature of $\mathrm{PE}$ at $1 \mathrm{~atm}$ is $0.28^{\circ} \mathrm{C} \mathrm{MPa}^{-1}$. Above $350 \mathrm{MPa}$, a phase transition from orthorhombic to the hexagonal phase (high pressure phase) occurs. Furthermore, the so called extended chain crystal (ECC) is formed by melt-crystallization of pure PE under high pressure.

This paper reports the melting phase diagram of a PE/1,2,4,5-TCB pseudo binary mixture under high pressures up to $400 \mathrm{MPa}$. Differential thermal analysis (DTA) was carried out under high pressure for the binary mixture. Pressure dependence of the eutectic temperature was determined. The effect of $1,2,4,5-\mathrm{TCB}$ on the phase transition of PE under high pressure was also investigated. The melting behavior of the high pressure crystal- 


\section{NAKAFUKU}

lized binary mixture was studied by DTA at atmospheric pressure.

\section{EXPERIMENTAL}

The PE samples used in this study were unfractionated commercial grade high density PE, Hizex $2200 \mathrm{~J}$ of $M_{w}=40,000$ (Mitsui Petrochemical Industries Co.). The diluent 1,2,4,5-TCB (Wako Pure Chemical Industries, Ltd.) was used in the powder form as obtained. The powder PE sample was prepared by evaporation of the xylene solvent after crystallization from the solution of the original pellet sample. The powder of $20 \mathrm{mg}$ of the binary mixture for each of various composition ratios was sealed in a glass tube $1.7 \mathrm{~mm}$ in inner diameter, and the glass tube was placed in an oil bath at $200^{\circ} \mathrm{C}$ to homogenize the mixture. After keeping the sample at the same temperature for $25 \mathrm{~min}$, it was quenched to room temperature. The sample was taken from the glass tube and cut $(1.7 \mathrm{~mm}$ in length) and tightly wrapped in aluminium foil to prevent sublimation of 1,2,4,5-TCB during heating. The sample and junction of the reference thermocouple were covered by epoxy resin independently. The high pressure DTA apparatus used in this study is described elsewhere. ${ }^{5}$ The heating rate of the DTA measurement was $6 \mathrm{~K} \mathrm{~min}^{-1}$ and the cooling rate, $\sim 5 \mathrm{~K} \mathrm{~min}^{-1}$. The rates of DTA under high pressure could not be changed much. Therefore, DTA was performed for the sample crystallized at a cooling rate of $\sim 5 \mathrm{~K} \mathrm{~min}^{-1}$ at $1 \mathrm{~atm}$ or high pressure below $300 \mathrm{MPa}$. The maximum temperature of the DTA cell was $300^{\circ} \mathrm{C}$. The effect of scan speed on the shape and peak temperature in the DTA curve was examined at $1 \mathrm{~atm}$. At a scan speed of $1.7 \mathrm{~K}$ $\min ^{-1}$, two peaks appeared in the DTA curve though both were small and the melting peak temperatures of PE, 1,2,4,5-TCB and the eutectic phase were lower about $2^{\circ} \mathrm{C}$ than these at a scan speed of $6 \mathrm{~K} \mathrm{~min}^{-1}$. The melting peak also shifted depending on sample size in a manner such that, the larger the sample size, the higher the peak temperature. However, the shift did not depend on pressure.

\section{RESULTS AND DISCUSSION}

\section{Phase Diagram of $P E / 1,2,4,5-T C B$ Binary Mixture at Elevated Pressure}

The DTA melting curves at $1 \mathrm{~atm}$ of the PE/ 1,2,4,5-TCB pseudo binary mixture are shown in Figure 1. Two endothermic peaks were observed for all DTA curves except for the weight fraction of $\mathrm{PE}\left(W_{\mathrm{PE}}\right)=0$. The lower temperature peak was located at $\sim 120^{\circ} \mathrm{C}$ for all weight fractions of PE. The higher temperature peak in the sample of $W_{\mathrm{PE}}$ greater than 0.6 was attributed to the melting of excess PE crystal, and below 0.6 in $W_{\mathrm{PE}}$ to the melting of excess diluent crystal. The phase diagram of the binary mixture at $1 \mathrm{~atm}$ was obtained by plotting the peak temperatures of melting against the weight fraction of $\mathrm{PE}$, as shown in

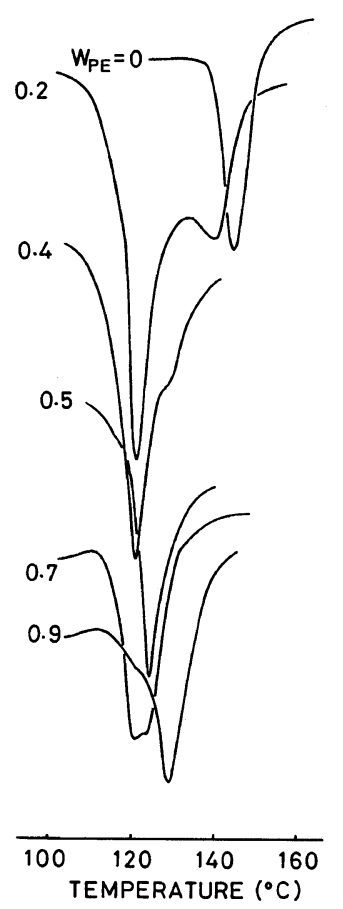

Figure 1. DTA curve of the melting of $\mathrm{PE} / 1,2,4,5-\mathrm{TCB}$ at $1 \mathrm{~atm}$. 


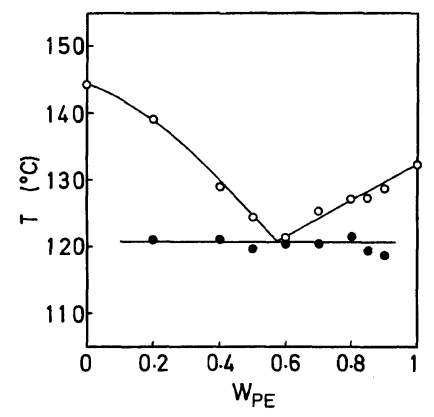

Figure 2. Phase diagram of the binary mixture of $\mathrm{PE} / 1,2,4,5-\mathrm{TCB}$.

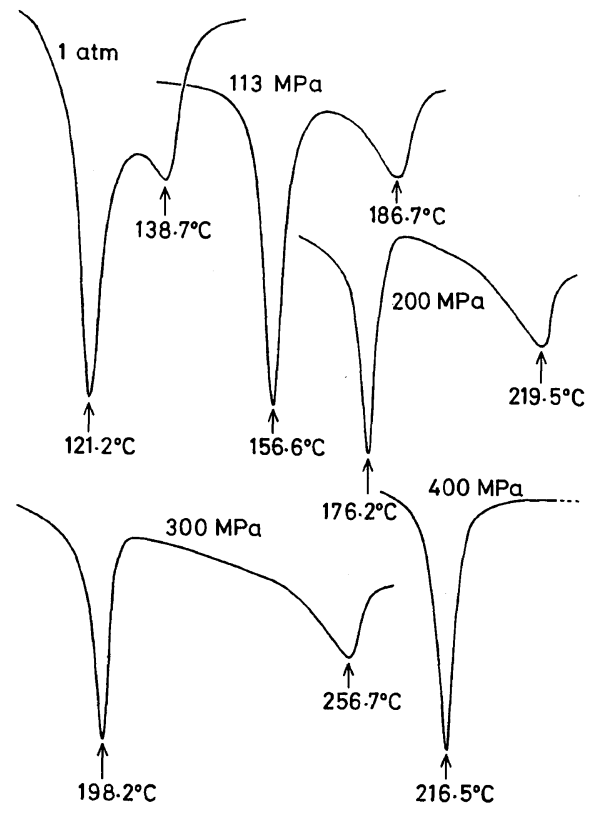

Figure 3. DTA curves of the melting of the PE/1,2,4,5TCB mixture of $W_{\mathrm{PE}}=0.2$ at $1 \mathrm{~atm}$ and high pressure.

Figure 2. Smith and Pennings constructed the phase diagram by extrapolating end melting temperatures and the peak temperature of the eutectic melting to zero scan speed, but the phase diagram at elevated pressure in this work was drawn from the data obtained at a scan speed of $6 \mathrm{~K} \mathrm{~min}^{-1}$, as described above.

Figure 3 shows the DTA melting curve at an elevated pressure of the sample of $W_{\mathrm{PE}}=$ 0.2 (hypoeutectic region on $\mathrm{PE}$ in the phase diagram). Both peaks shifted to the high tem-

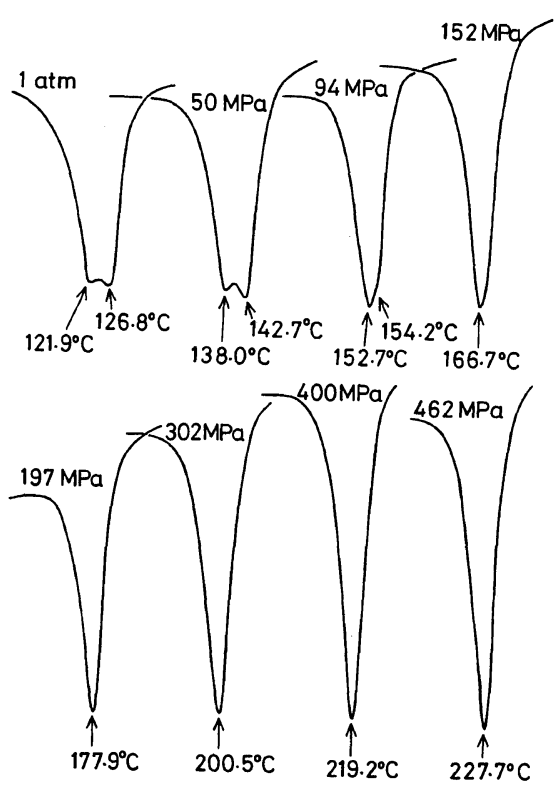

Figure 4. DTA curves of the melting of the PE/1,2,4,5TCB mixture of $W_{\mathrm{PE}}=0.8$ at $1 \mathrm{~atm}$ and high pressure.

perature side with increasing pressure, and the difference in $T_{\mathrm{m}}$ between 1,2,4,5-TCB (high temperature peak) and the eutectic melting (low temperature peak) also increased with pressure because of the difference in the pressure dependence of $T_{\mathrm{m}}$.

Figure 4 shows the DTA melting curve of the sample of $W_{\mathrm{PE}}=0.8$ (hypereutectic region on $\mathrm{PE}$ ) at an elevated pressure. Two peaks due to the melting of PE (higher temperature peak) and the eutectic melting (lower temperature peak) shifted to the high temperature side with pressure, and both peaks approached each other at elevated pressures. Above 150. $\mathrm{MPa}$, only a single peak was observed. In the high PE content sample, the difference between $T_{\mathrm{m}}$ of $\mathrm{PE}$ and the eutectic melting temperature at $1 \mathrm{~atm}$ was large, and the single endothermic peak begin to appear at higher pressures. For example, in the case of $W_{\mathrm{PE}}=0.9$, the single peak appeared at $350 \mathrm{MPa}$.

Figure 5 shows the pressure dependence of $T_{\mathrm{m}}$ of PE and 1,2,4,5-TCB and the eutectic melting temperature for the sample at various 
compositions. $T_{\mathrm{m}}$ of pure 1,2,4,5-TCB increased with pressure almost linearly and that of $1,2,4,5-\mathrm{TCB}$ in the binary mixture only

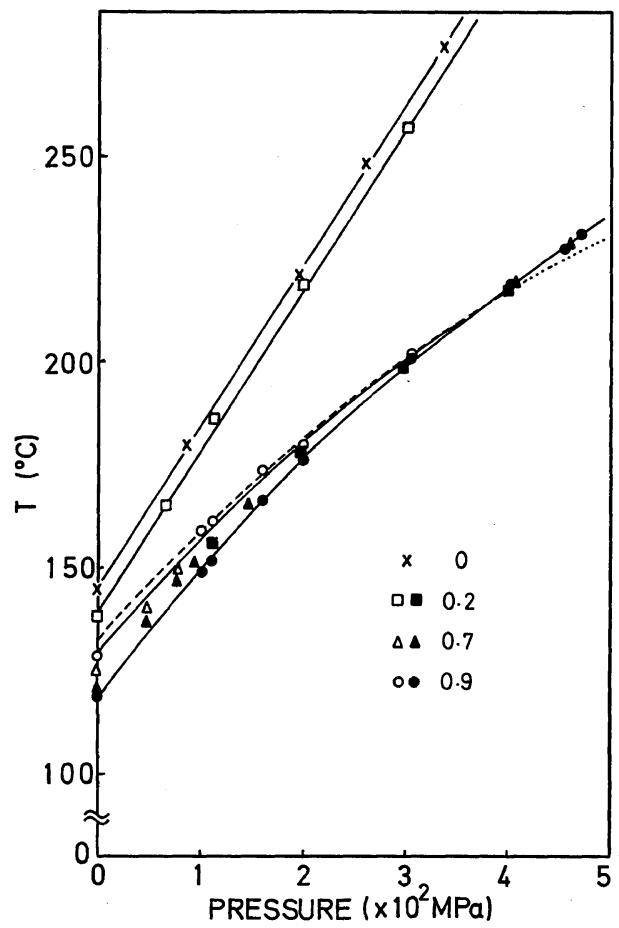

Figure 5. Pressure dependence of $T_{\mathrm{m}}$ of $\mathrm{PE}$ and $1,2,4,5-\mathrm{TCB}$ and the eutectic temperature of the binary mixture for various weight fractions of PE. $\times, 0 ; \square \mathbf{E}$, $0.2 ; \triangle \boldsymbol{\Lambda}, 0.7 ; \bigcirc \mathbf{0}, 0.9$. Filled marks are for lower temperature peaks. shifted to the low temperature side with decreasing 1,2,4,5-TCB content. The dashed curve in the figure shows the pressure dependence of $T_{\mathrm{m}}$ of folded chain crystals (FCC) of pure $\mathrm{PE}$. The melting curve of pure $\mathrm{PE}$ crossed that of the eutectic melting at about $350 \mathrm{MPa}$, but in the pseudo binary mixture, inversion of the two peaks did not occur even in the sample of $90 \% \mathrm{PE}$ content in the figure. Thus, $T_{\mathrm{m}}$ of FCC in the binary mixture shifted to the high temperature side above the pressure where the two melting curves crossed. The melting curves in Figure 5 were fitted to the quadratic equation

$$
T_{\mathrm{m}}=A+B P-C P^{2}
$$

by the least squares method. In this equation, $T_{\mathrm{m}}$ is the peak melting temperature of $\mathrm{PE}$, $1,2,4,5-\mathrm{TCB}$ and the eutectic phase and $P$ is the pressure in $\mathrm{MPa}$. The coefficients $A, B$, and $C$ were determined for all samples at various compositions. The coefficients for the eutectic melting were determined using the data from $1 \mathrm{~atm}$ to $500 \mathrm{MPa}$, but those for PE by the data from $1 \mathrm{~atm}$ to the pressure at which a single peak begin to appear on the DTA curve. Table I lists all the values of $A, B$, and $C$ for all compositions in the binary mixture. The value of $B$ exhibited the pressure dependence of $T_{\mathrm{m}}$

Table I. $A, B$, and $C$ in the equation, $T_{\mathrm{m}}=A+B P-C P^{2}$, for the high temperature peak $\left(T_{\mathrm{m}}(H)\right)$ and low temperature peak $\left(T_{\mathrm{m}}(L)\right)$ on the DTA curve

\begin{tabular}{|c|c|c|c|c|c|c|}
\hline \multirow{3}{*}{$W_{\mathrm{PE}}$} & \multicolumn{3}{|c|}{$T_{\mathrm{m}}(H)$} & \multicolumn{3}{|c|}{$T_{\mathrm{m}}(L)$} \\
\hline & $A$ & $B$ & $C$ & $A$ & $B$ & $C$ \\
\hline & ${ }^{\circ} \mathrm{C}$ & ${ }^{\circ} \mathrm{C} \mathrm{MPa}^{-1}$ & ${ }^{\circ} \mathrm{CMPa}^{-2}$ & ${ }^{\circ} \mathrm{C}$ & ${ }^{\circ} \mathrm{CMPa}^{-1}$ & ${ }^{\circ} \mathrm{CMPa}^{-2}$ \\
\hline 0 & 144.1 & 0.42 & $0.643 \times 10^{-4}$ & & & \\
\hline 0.2 & 138.7 & 0.43 & 1.32 & 122.0 & 0.32 & $2.09 \times 10^{-4}$ \\
\hline 0.4 & 129.1 & 0.42 & 1.07 & 122.0 & 0.31 & 1.95 \\
\hline 0.5 & 125.0 & 0.42 & 1.21 & 120.6 & 0.33 & 2.20 \\
\hline 0.6 & 121.9 & 0.49 & 22.4 & 121.7 & 0.33 & 2.15 \\
\hline 0.7 & 125.2 & 0.36 & 8.32 & 120.5 & 0.36 & 2.72 \\
\hline 0.8 & 126.8 & 0.34 & 4.79 & 122.5 & 0.32 & 2.08 \\
\hline 0.85 & 127.7 & 0.31 & 2.38 & 120.2 & 0.35 & 2.54 \\
\hline 0.9 & 128.4 & 0.32 & 2.79 & 118.2 & 0.33 & 1.93 \\
\hline 1 & 132.4 & 0.28 & 1.65 & & & \\
\hline
\end{tabular}




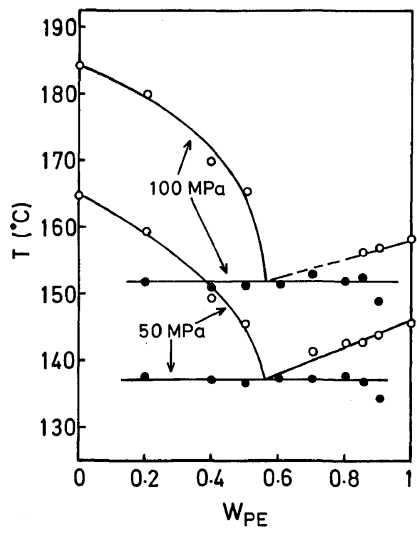

(a)

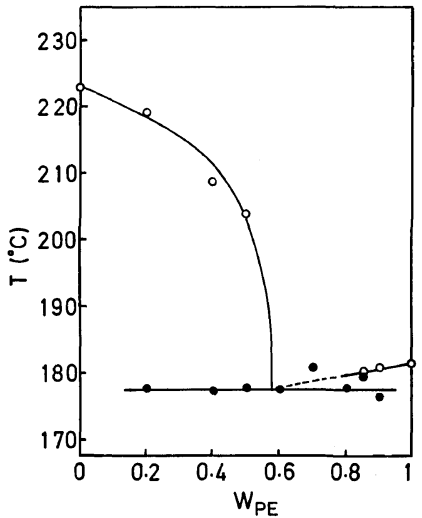

(b)

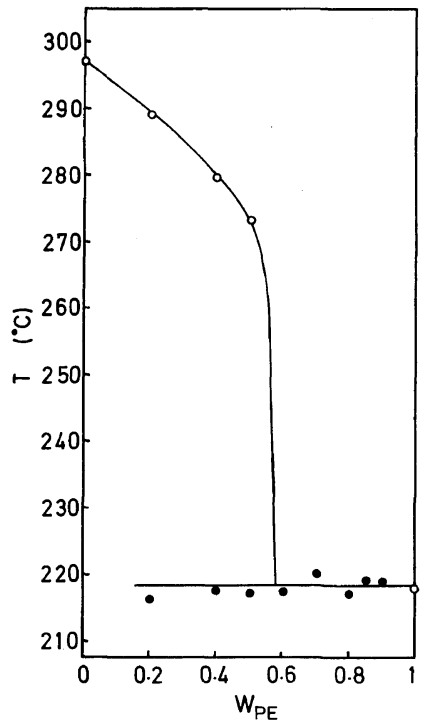

(c)

Figure 6. Phase diagram of $\mathrm{PE} / 1,2,4,5-\mathrm{TCB}$ at high pressure. (a) 50 and $100 \mathrm{MPa}$; (b) $200 \mathrm{MPa}$; (c) $400 \mathrm{MPa}$. at approximately $1 \mathrm{~atm}\left(\mathrm{~d} T_{\mathrm{m}} / \mathrm{d} P\right)$. The average value of $\mathrm{d} T_{\mathrm{m}} / \mathrm{d} P$ of $1,2,4,5-\mathrm{TCB}$ in the mixture was $0.42^{\circ} \mathrm{C} \mathrm{MPa}^{-1}$ which is $\sim 0.14^{\circ} \mathrm{C} \mathrm{MPa}^{-1}$ higher than that of pure $\mathrm{PE}$. The pressure dependence of the temperature of the eutectic melting was nearly the same for all samples with different compositions. The average value of $\mathrm{d} T_{\mathrm{m}} / \mathrm{d} P$ of the eutectic melting was $0.33^{\circ} \mathrm{C}$ $\mathrm{MPa}^{-1}$ which is $0.05^{\circ} \mathrm{C} \mathrm{MPa}^{-1}$ higher than the value for $\mathrm{FCC}$ in pure $\mathrm{PE}$ but $0.09^{\circ} \mathrm{C} \mathrm{MPa}^{-1}$ lower than that of $1,2,4,5$-TCB.

The experimental phase diagram of $\mathrm{PE} /$ 1,2,4,5-TCB pseudo binary mixture under high pressure was determined using the values of Table I. Figure 6 shows the pressure change in the phase diagram of $\mathrm{PE} / 1,2,4,5-\mathrm{TCB}$ pseudo binary mixture. In the hypoeutectic region of PE, excess 1,2,4,5-TCB crystal existed without melting in the eutectic solutions up to a temperature about $60^{\circ} \mathrm{C}$ higher than the eutectic melting temperature at $400 \mathrm{MPa}$. In contrast, the difference of $T_{\mathrm{m}}$ in $\mathrm{PE}$ and the eutectic melting temperature decreased with increasing pressure in the hypereutectic region in the phase diagram, and above $350 \mathrm{MPa}$, all $\mathrm{PE}$ and 1,2,4,5-TCB crystals melted simultaneously at the eutectic melting temperature. In the crystallization process, well separated exothermic double peaks were observed on the DTA curve even at $456 \mathrm{MPa}$ at $W_{\mathrm{PE}}=0.8$, though these two peaks approach each other with pressure.

Effect of 1,2,4,5-TCB on the Melting and Crystallization of PE under High Pressure

The DTA curve of melting of pure PE under high pressure above $350 \mathrm{MPa}$ was more complicated than the DTA curve of melting at $1 \mathrm{~atm}$. Figure 7(a) shows the DTA curve of melting at $460 \mathrm{MPa}$ of pure PE crystallized from the melt at $1 \mathrm{~atm}$. Three endothermic peaks were observed in the heating process: $P_{1}$ peak was attributed to the melting of FCC and $\mathrm{P}_{2}$ peak to the orthorhombic to hexagonal phase transition and $\mathrm{P}_{3}$ peak to the melting of the hexagonal phase. ${ }^{6,7}$ The DTA melting 


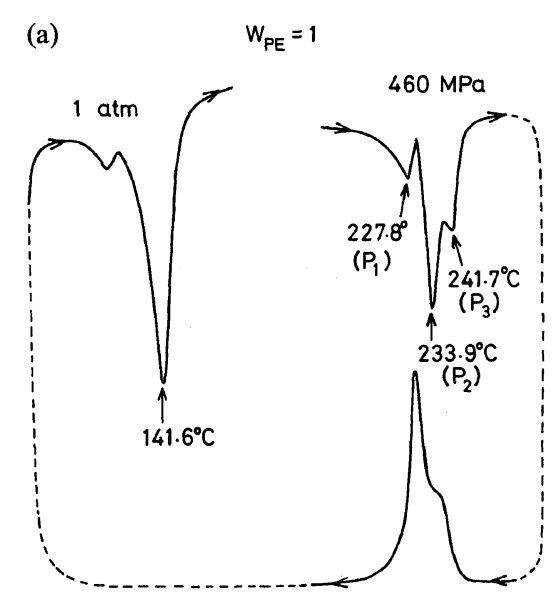

(b) $W_{P E}=0.8$

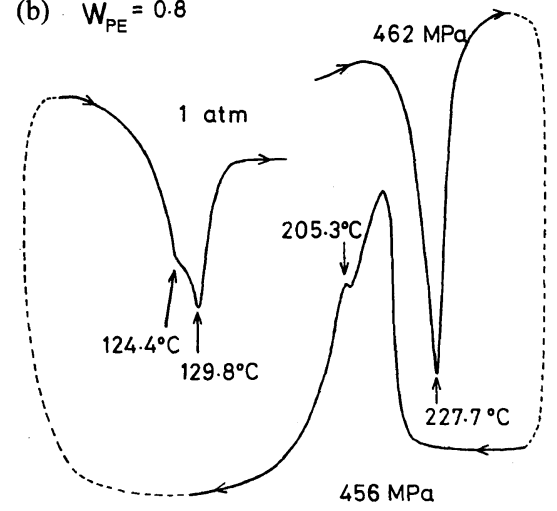

(c)

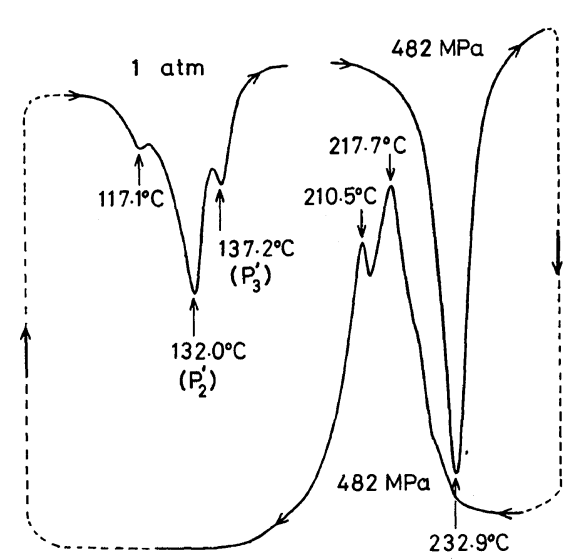

Figure 7. DTA curve of melting and crystallization under high pressure above $450 \mathrm{MPa}$ of pure $\mathrm{PE}$ and the $\mathrm{PE} / 1,2,4,5$-TCB binary mixture and DTA curve at $1 \mathrm{~atm}$ of the sample crystallized at high pressure. (a) pure PE; (b) $W_{\mathrm{PE}}=0.8$; (c) $W_{\mathrm{PE}}=0.8$. curve of the pseudo binary mixture of PE and 1,2,4,5-TCB under high pressure differed from the DTA curve of pure PE. In the hypoeutectic region in the phase diagram, two separated peaks due to the melting of $1,2,4,5-\mathrm{TCB}$ (high melting temperature peak) and the eutectic melting appeared in the DTA curve as mentioned already. In the hypereutectic region, only the single peak was observed in the DTA curve above the pressure where two peaks overlaps, as shown in Figure 7(b). Therefore, the ortho-hexagonal transition of PE under high pressure was assumed not to occur in the melting process in the pseudo binary mixture. The peak temperature $\left(232.9^{\circ} \mathrm{C}\right)$ at $482 \mathrm{MPa}$ was $4.3^{\circ} \mathrm{C}$ higher than that of melting of FCC of pure $\mathrm{PE}$ at the same pressure. This behavior of melting of PE under high pressure may be characteristic of the mixture with the low molecular weight high melting temperature diluent. In the polymer-polymer mixture, for example, the $\mathrm{PE} /$ polypropylene blend, the DTA melting curve of PE showed three endothermic peaks, as in the melting of pure PE at high pressure, and the melting peaks shifted to the low temperature side with decreasing PE content. $^{8}$

The high pressure crystallization of pure $\mathrm{PE}$ produced ECC which melted at about $142^{\circ} \mathrm{C}$ at $1 \mathrm{~atm}$ as shown in Figure 7(a). The DTA melting curve at $1 \mathrm{~atm}$ of the binary mixture $\left(W_{\mathrm{PE}}=0.8\right)$ crystallized at $460 \mathrm{MPa}$ showed two peaks due to the melting of PE (high temperature peak) and the eutectic melting as shown in Figure 7(b). On the DTA curve at $1 \mathrm{~atm}$ of the sample of $W_{\mathrm{PE}}=0.8$ crystallized from the melt at $482 \mathrm{MPa}$, a small peak $\left(\mathrm{P}_{3}^{\prime}\right)$ was observed on the high temperature side of the $\mathrm{P}_{2}^{\prime}$ peak as shown in Figure $7(\mathrm{c})$. The melting temperature of the $\mathrm{P}_{3}^{\prime}$ peak was lower than the melting temperature of ECC but much higher than that of FCC in pure PE. This suggests that a small amount of ECC with lower melting temperature than the usual ECC of $\mathrm{PE}$ is formed by melt-crystallization of $W_{\mathrm{PE}}=0.8$ sample under high pressure at 482 
$\mathrm{MPa}$. In the sample of $W_{\mathrm{PE}}=0.9$ crystallized at $474 \mathrm{MPa}$, the high temperature peak or shoulder was also observed in the DTA curve at $1 \mathrm{~atm}$. A lowering of the melting temperature and decrease in ECC content of PE have already been reported for the high pressure crystallized $\mathrm{PE} / \mathrm{xylene}^{9}$ and $\mathrm{PE} /$ paraffin $^{10} \mathrm{mix}$ tures, but the interruption effect of $1,2,4,5$ TCB on the ECC formation of PE under high pressure was stronger than the other diluents described above in a pressure range up to 500 $\mathrm{MPa}$. Morphological investigation on the high pressure crystallized $\mathrm{PE} / 1,2,4,5-\mathrm{TCB}$ pseuso binary mixture is now underway.

\section{CONCLUSION}

On the basis of the DTA study on the melting of $\mathrm{PE} / 1,2,4,5$-TCB pseudo binary mixture at high pressure, the phase diagram of the mixture at elevated pressures up to $400 \mathrm{MPa}$ was determined. In the hypoeutectic region of the phase diagram of melting temperature as a function of the weight fraction of $\mathrm{PE}$, the temperature difference between the liquidus curve of 1,2,4,5-TCB and the eutectic point was found to increase with pressure. In the hypereutectic region, the temperature difference between the liquidus curve of $\mathrm{PE}$ and the eutectic point decreased with pressure, and the liquidus curve of $\mathrm{PE}$ corresponded to the eutectic horizontal above $350 \mathrm{MPa}$. The pressure dependence of the eutectic point was $0.33^{\circ} \mathrm{C} \mathrm{MPa}^{-1}$ or $0.09^{\circ} \mathrm{C} \mathrm{MPa}^{-1}$ lower than that of $1,2,4,5-\mathrm{TCB}$ melting temperature but, $0.05^{\circ} \mathrm{CPa}^{-1}$ higher than that of pure $\mathrm{PE}$ melting temperature.

In the melting process at high pressure above $350 \mathrm{MPa}$, pure PE showed the orthrhombic to hexagonal phase transition below the melting temperature, but in the PE/1,2,4,5TCB pseudo binary mixture, no phase transition occurred. The DTA curve at $1 \mathrm{~atm}$ of the binary mixture crystallized from the melt at about $500 \mathrm{MPa}$ showed a small peak at higher temperature than the melting peak of $\mathrm{PE}$, suggesting the formation of a small amount of ECC which melts about $5^{\circ} \mathrm{C}$ lower temperature than the melting temperature of the usual ECC obtained by the high pressure crystallization of pure PE.

\section{REFERENCES}

1. P. Smith and A. J. Pennings, J. Mater. Sci., 11, 1450 (1976).

2. A. J. Pennings and P. Smith, Br. Polym. J., 1, 460 (1975).

3. P. Smith and A. J. Pennings, Polymer, 15, 413 (1974).

4. B. Wunderlich, "Macromolecular Physics," Vol. 3, Academic Press, Inc., New York, N.Y., 1980, pp 91-96.

5. Y. Miyamoto, C. Nakafuku, and T. Takemura, Polym. J., 3, 122 (1972).

6. M. Yasuniwa, C. Nakafuku, and T. Takemura, Polym. J., 4, 526 (1973).

7. D. C. Bassett and B. Turner, Nature (London), Phys. Sci., 240, 146 (1972).

8. C. Nakafuku, Polym. J., 15, 641 (1983).

9. T. Arikawa, S. Miyata, and K. Sakaoku, Abstracts of Papers, SPSJ 22nd Symposium, Tokyo, November 8, 1973, p I-459.

10. K. Sugioka, Y. Fujiwara, K. Monobe, and J. Osugi, Abstracts of Papers, SPSJ 22nd Symposium, Tokyo, November 8, 1973, p I-465. 